\title{
Necdin modulates leukemia-initiating cell quiescence and chemotherapy response
}

\author{
Chonghua Yao ${ }^{1, *}$, Michihiro Kobayashi ${ }^{2,}{ }^{*}$, Sisi Chen ${ }^{3}$, Sarah C. Nabinger ${ }^{2}$, Rui Gao ${ }^{2}$, \\ Stephen Z. Liu ${ }^{2}$, Takashi Asai ${ }^{4}$ and Yan Liü, \\ ${ }^{1}$ Department of Rheumatism, Shanghai Municipal Hospital of Traditional Chinese Medicine, Shanghai University of Traditional \\ Chinese Medicine, Shanghai, China \\ ${ }^{2}$ Department of Pediatrics, Herman B Wells Center for Pediatric Research, Indiana University School of Medicine, Indianapolis, \\ IN, USA \\ ${ }^{3}$ Department of Biochemistry and Molecular Biology, Indiana University School of Medicine, Indianapolis, IN, USA \\ ${ }^{4}$ Sylvester Comprehensive Cancer Center, Miller School of Medicine, University of Miami, Miami, FL, USA \\ *Co-first authors, These authors have contributed equally to this work
}

Correspondence to: Yan Liu, email: liv219@iu.edu

Keywords: Necdin, leukemia-initiating cells, quiescence, MLL-AF9, chemotherapy

Received: March 13, $2017 \quad$ Accepted: August 26, $2017 \quad$ Published: September 18, 2017

Copyright: Yao et al. This is an open-access article distributed under the terms of the Creative Commons Attribution License 3.0 (CC BY 3.0), which permits unrestricted use, distribution, and reproduction in any medium, provided the original author and source are credited.

\section{ABSTRACT}

Acute myeloid leukemia (AML) is a devastating illness which carries a very poor prognosis, with most patients living less than 18 months. Leukemia relapse may occur because current therapies eliminate proliferating leukemia cells but fail to eradicate quiescent leukemia-initiating cells (LICs) that can reinitiate the disease after a period of latency. While we demonstrated that p53 target gene Necdin maintains hematopoietic stem cell (HSC) quiescence, its roles in LIC quiescence and response to chemotherapy are unclear. In this study, we utilized two well-established murine models of human AML induced by MLL-AF9 or AML1-ETO9a to determine the role of Necdin in leukemogenesis. We found that loss of Necdin decreased the number of functional LICs and enhanced myeloid differentiation in vivo, leading to delayed development of leukemia induced by MLL-AF9. Importantly, Necdin null LICs expressing MLL-AF9 were less quiescent than wild-type LICs. Further, loss of Necdin enhanced the response of MLL-AF9+ leukemia cells to chemotherapy treatment, manifested by decreased viability and enhanced apoptosis. We observed decreased expression of $\mathrm{BCl} 2$ and increased expression of $p 53$ and its target gene Bax in Necdin null leukemia cells following chemotherapy treatment, indicating that p53-dependent apoptotic pathways may be activated in the absence of Necdin. In addition, we found that loss of Necdin decreased the engraftment of AML1-ETO9a+ hematopoietic stem and progenitor cells in transplantation assays. However, Necdin-deficiency did not affect the response of AML1-ETO9a+ hematopoietic cells to chemotherapy treatment. Thus, Necdin regulates leukemia-initiating cell quiescence and chemotherapy response in a context-dependent manner. Our findings suggest that pharmacological inhibition of Necdin may hold potential as a novel therapy for leukemia patients with MLL translocations. 


\section{INTRODUCTION}

Acute myeloid leukemia (AML) is the most common acute leukemia in adults. It usually occurs around age 60 with no identifiable cause and it carries a very poor prognosis, with most patients living less than 18 months [1]. Leukemia can be viewed as a malignancy initiated in a hematopoietic stem cell (HSC) or primitive progenitor cell that has maintained or acquired the capacity for self-renewal and is blocked in its ability to differentiate by the accumulation of a series of mutations and/or epigenetic changes [2-4]. The initial treatment of leukemia is designed to achieve a complete remission, meaning that the leukemic cells are not detectable in the bone marrow and normal blood formation has recovered. Leukemia relapse may occur because current therapies eliminate proliferating cells (that constitute the bulk of the disease) but fail to eradicate dormant leukemiainitiating cells (LICs) that can reinitiate the disease after a period of latency (the duration of remission) [1-2]. LICs, and in particular those that are in a dormant state, are resistant to chemotherapy or targeted therapies [5-7]. The development of new therapeutic approaches that can target LICs will have a profound impact on our ability to eradicate leukemia [8-10]. Unfortunately, little progress has been made in treating AML over the past 4 decades [1]. Clearly, new treatment strategies are urgently needed.

AML is characterized by recurrent chromosomal translocations, which generally target transcriptional regulatory genes, generating fusion proteins like MLL-AF9 and AML1-ETO [11-12]. MLL is a histone methyltransferase and MLL-AF9 is a $170 \mathrm{kDa}$ fusion protein, generated by the $t(9 ; 11)$ [11]. MLL-AF9 is a frequently occurring MLL fusion oncogene typically associated with the FAB-M4 or M5 subtypes of human AML [11]. MLL associated leukemia accounts for the majority of infant leukemia, approximately $10 \%$ of adult de novo leukemia and approximately $33 \%$ of therapy related acute leukemia with a balanced chromosome translocation [11]. The presence of an MLL rearrangement generally confers a poor prognosis $[1,11]$. MLL-AF9 is capable of transforming hematopoietic progenitor cells (HPCs) and HSCs, thus it can impart self-renewal to a nonself-renewing cell [13].

The $\mathrm{t}(8 ; 21)(\mathrm{q} 22 ; \mathrm{q} 22)$ translocation is one of the most common genetic abnormalities in acute myeloid leukemia (AML), identified in $15 \%$ of all cases of AML, including $40-50 \%$ of FAB M2 subtype and rare cases of M0, M1 and M4 subtypes [12]. AML1-ETO is insufficient to cause acute leukemia by itself in human or mouse cells [14-15]. However, a truncated form of the AML1-ETO fusion protein (called AML1-ETO exon 9a) is sufficient to cause leukemia in mice, with a rather short latency

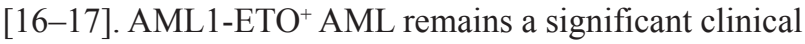
problem, with $30 \%$ of patients relapsing and long-term survival rates ranging between 30 and $60 \%$, indicating the need for improved therapeutic approaches [18-19].
We are turning our attention to leukemia-initiating cells (LICs) to generate additional knowledge in order to develop therapeutic strategies that can eliminate the largely quiescent LICs and improve leukemia treatment. We have defined a critical role for $\mathrm{p} 53$ in regulating hematopoietic stem cell quiescence, and identified Necdin as a p53 target gene whose promoter binds and is transactivated by $\mathrm{p} 53$ [20-21]. Necdin is a growth suppressing protein first identified in post-mitotic neurons [22-23] and the gene encoding Necdin is one of several genes that are deleted in individuals with Prader-Willi syndrome [24]. Like the retinoblastoma protein, Necdin interacts with multiple cell cycle promoting proteins, such as simian virus 40 large $\mathrm{T}$ antigen, adenovirus E1A and the transcription factor E2F1 [25-27]. Necdin is highly expressed in long-term hematopoietic stem cells, and we have demonstrated that Necdin functions as a rheostat controlling HSC quiescence $[21,28]$. Necdin null HSCs are more cycling and more easily exhausted, suggesting that Necdin is required for HSC maintenance [21].

Given that Necdin is essential for HSC quiescence and some patients with Prader-Willi syndrome develop AML [20-21, 29], we hypothesized that Necdin deficiency will stimulate quiescent LICs to enter the cell cycle and sensitize them to chemotherapy and improve leukemia treatment. To test this, we utilized two well-established mouse models of human AML, including MLL-AF9 and AML1-ETO9a, to determine the role of Necdin in LIC proliferation and chemotherapy response $[13,16]$. We discovered that loss of Necdin decreased the quiescence of MLL-AF9+ ${ }^{+}$LICs and sensitized leukemia cells expressing MLL-AF9 to chemotherapy treatment.

\section{RESULTS}

\section{Necdin deficiency enhances the proliferation of hematopoietic progenitor cells expressing MLL-AF9}

We utilized a mouse model of human AML induced by the MLL-AF9 oncogene to determine the role of Necdin in the initiation and progression of AML [13]. We infected wild type and Necdin null fetal liver cells, which contain hematopoietic stem and progenitor cells (HSPCs), with retroviruses expressing GFP or MLL-AF9. Robust expression of the GFP was seen $72 \mathrm{~h}$ post-infection (Figure 1A). We cultured transduced cells $\left(\mathrm{GFP}^{+}\right)$in serum free medium in the presence of cytokines for seven days and then examined the frequency of HSPCs. We found that loss of Necdin increased the frequency of $\mathrm{Kit}^{+} \mathrm{CD} 11 \mathrm{~b}-\mathrm{Gr} 1^{-}$ cells and decreased the frequency of $\mathrm{Kit}^{+} \mathrm{CD} 11 \mathrm{~b}^{+} \mathrm{Gr} 1^{+}$cells (Figure 1B and 1C). Given that leukemia-initiating cells or leukemia stem cells (LSCs) in murine model of MLL$\mathrm{AF9}^{+} \mathrm{AML}$ are $\mathrm{Kit}^{+} \mathrm{CD} 11 \mathrm{~b}^{+} \mathrm{Gr} 1^{+}$cells $[13,30]$, our finding suggests that Necdin-deficiency may decrease the number of LICs in MLL-AF9-induced leukemia. 
In the serial replating assay, wild-type fetal liver cells cannot be replated more than three times (Figure 1D). While Necdin null HSPCs show decreased colony formation in week 1 , the replating potentials of Necdin null cells and wild-type cells are comparable (Figure 1D). We then performed serial replating assays using wild type and Necdin null fetal liver cells expressing MLL-AF9. While Necdin null cells show decreased colony formation in week one compared to wild-type cells, they show enhanced colony formation potential compared to wild-type cells in following weeks (Figure 1E). To determine the effect of Necdin deficiency on HSPC proliferation, we cultured wild type and Necdin null fetal liver cells expressing MLL-AF9 in medium containing hematopoietic cytokines. 48 and 72 hours later, we counted cell number using flow cytometry and found that expression of MLL-AF9 enhanced the proliferation of Necdin null HSPCs compared to wild type HSPCs (Figures $1 \mathrm{~F}$ and $1 \mathrm{G}$ ).

\section{Necdin deficiency delays the progression of leukemia-induced by MLL-AF9}

To determine the role of Necdin in MLL-AF9induced leukemia, we transplanted 100,000 wild type or Necdin null HSPCs expressing MLL-AF9 cells (CD45.2 ${ }^{+}$ $\mathrm{GFP}^{+}$) into lethally irradiated recipient mice (B6.SJL mice, $\mathrm{CD} 45.1^{+}$) together with 100,000 normal competitor cells $\left(\mathrm{CD} 45.1^{+}\right)$. We monitored leukemia progression in recipient mice by checking $\mathrm{GFP}^{+}$leukemic cells in the peripheral blood every 4 weeks. We observed rapid expansion of $\mathrm{GFP}^{+}$leukemia cells in recipient mice repopulated with both wild -type and Necdin null HSPCs expressing MLL-AF9 at 4 weeks following transplantation (Figures 2A and 2B). We observed several population of $\mathrm{Gr}^{+}$cells with different GFP intensity in the peripheral blood of recipient mice repopulated with Necdin null HSPCs expressing MLL-AF9 (Figure 2A), suggesting that Necdin may affect the differentiation of LICs expressing MLL-AF9.

In the bone marrow transduction and transplantation model of MLL-AF9, all recipient mice developed AML, with a median latency of 84.5 days [13]. We utilized fetal liver cells and obtained similar results. There is no apparent effect of Necdin deficiency on the survival of recipient mice and all recipient mice transplanted with wild type or Necdin null mice died 11 weeks following transplantation (Figure 2C), suggesting that Necdin is dispensable for the initiation and/or progression of leukemia induced by MLL-AF9 in primary transplantation assays. We transplanted $3 \times 10^{6} \mathrm{GFP}^{+} \mathrm{MLL}^{-\mathrm{AF} 9}{ }^{+}$bone marrow cells $\left(\mathrm{CD} 45.2^{+}\right)$isolated from the primary recipient mice into lethally irradiated recipient mice (B6. $\mathrm{SJL}, \mathrm{CD} 45 \cdot 1^{+}$). We monitored leukemia development in recipient mice. While it takes 10 weeks for MLL-AF9 to induce leukemia in the primary recipient mice (Figure 2C), it only takes 3 weeks for these leukemia cells to develop leukemia in secondary recipients (Figure 2D). Importantly, we found that Necdin-deficiency significantly delayed leukemia onset (Figure 2D), suggesting that Necdin is important for the progression of leukemia induced by MLL-AF9 in transplantation assays.

Given that Necdin maintains HSC quiescence [2021] and GMPs (Lin-Sca1-IL7R-Kit ${ }^{+} \mathrm{Fc} \gamma \mathrm{RII} / \mathrm{III}^{\text {high }} \mathrm{CD} 34^{\text {high }}$ ) are leukemia-initiating cells (LICs) in MLL-AF9 induced leukemia [13], we examined the impact of Necdin deficiency on the quiescent state of GMPs using Ki67 and DAPI staining. We found that loss of Necdin significantly decreased the number of quiescent GMPs (Ki67') in the bone marrow of leukemia mice (Figure 2E), suggesting that Necdin maintains the quiescence of leukemiainitiating cells expressing MLL-AF9.

To further investigate the mechanisms by which Necdin deficiency delays leukemia progression, we examined the frequency of $\mathrm{Kit}^{+}$cells, GMPs, and $\mathrm{Gr}^{+} \mathrm{CD} 11 \mathrm{~b}^{+}$cells in the bone marrow of leukemia mice. We found that loss of Necdin decreased the frequency of $\mathrm{Kit}^{+}$cells and GMPs in the bone marrow (Figure 2F), suggesting that the number of LICs was decreased in the bone marrow of leukemia mice in the absence of Necdin. Further, we observed decreased number of mature myeloid cells $\left(\mathrm{Gr} 1^{+} \mathrm{CD} 11 \mathrm{~b}^{+}\right)$in the bone marrow of leukemia mice repopulated with Necdin null cells (Figure 2G), indicating that Necdin deficiency promotes myeloid differentiation. To determine the functional impact of Necdin deficiency on LICs, we performed serial replating assays. While Necdin null LICs (GMPs) generated more colonies than wild type cells in Week 1, these cells show decreased colony formation capability compared to wild type leukemia cells in following weeks (Figure $2 \mathrm{H})$, demonstrating that Necdin deficiency impairs LIC function in vitro.

\section{Loss of Necdin sensitizes leukemia cells expressing MLL-AF9 to chemotherapy}

Given that loss of Necdin decreased the quiescence of GMPs expressing MLL-AF9 (Figure 2E), we predicted that Necdin null leukemia cells expressing MLL-AF9 would be sensitive to chemotherapy. That was indeed the case. We treated wild type and Necdin null leukemia cells expressing MLL-AF9 with DMSO or different concentrations of chemotherapy drug cytarabine (AraC) and monitored cell viability by cell counting. While 24 hour AraC treatment did not affect the viability of leukemia cells expressing MLL-AF9 (Figure 3A), we found that Necdin null leukemia cells expressing MLLAF9 were sensitive to extended AraC treatment (48 hour) in a dosage-dependent manner, manifested by decreased viability (Figure 3B). While the LC50 for AraC on wild type leukemia cells is $0.16 \mu \mathrm{M}$, the LC50 for AraC on Necdin null leukemia cells expressing MLL-AF9 is 0.09 $\mu \mathrm{M}$. We then examined the impact of AraC treatment on 
A
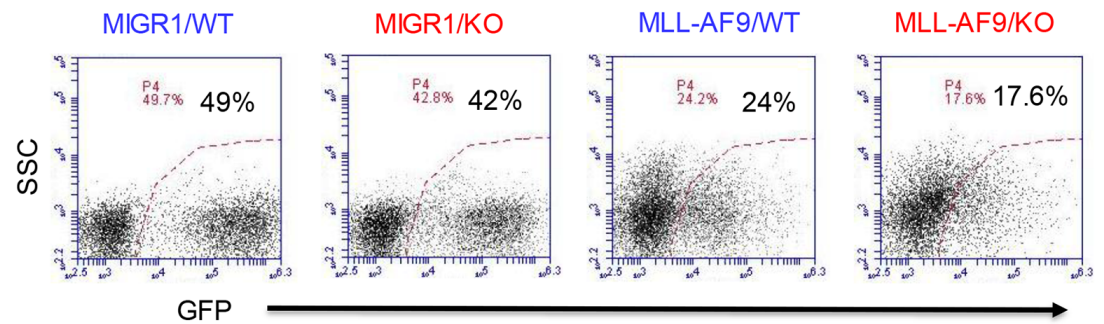

B
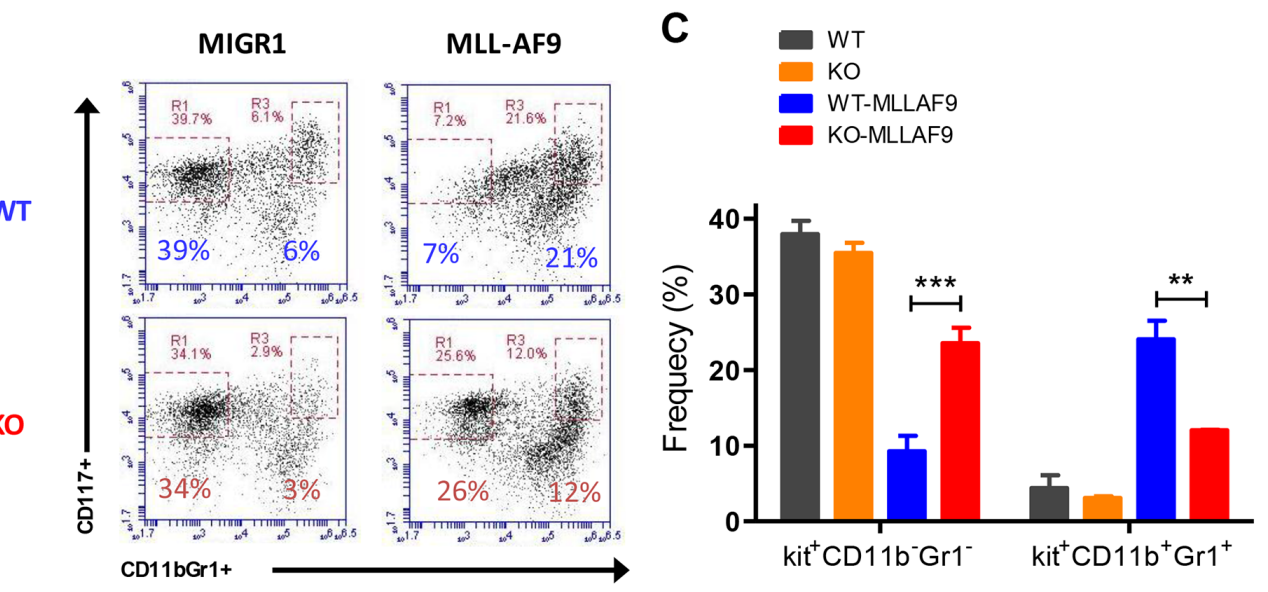

D

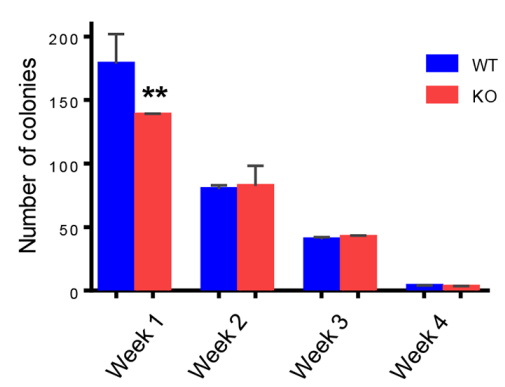

E

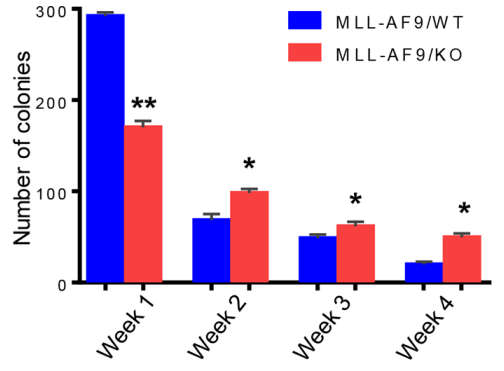

$\mathbf{F}$

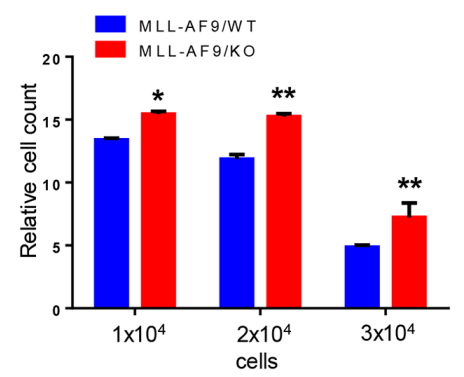

G

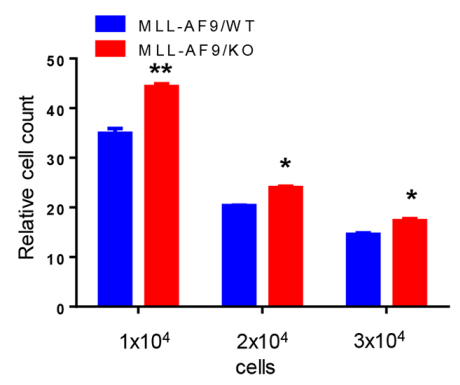

Figure 1: Necdin deficiency enhances the proliferation of hematopoietic progenitor cells expressing MLL-AF9. (A) Fetal liver cells isolated from wild-type (WT) or Necdin knock-out (KO) mice were transduced with retroviruses expressing GFP (MIGR1) or MLL-AF9. Representative flow cytometry plots show the frequency of transduced cells $\left(\mathrm{GFP}^{+}\right) 72$ hours following transduction. (B) Transduced wild type and Necdin null fetal liver cells $\left(\mathrm{GFP}^{+}\right)$were cultured in serum free medium in the presence of cytokines for seven days. The frequency of hematopoietic stem and progenitor cells was determined by flow cytometry analysis. Representative flow cytometry plots show the frequency of $\mathrm{Kit}^{+} \mathrm{CD} 11 \mathrm{~b}-\mathrm{Gr}^{-}$and $\mathrm{Kit}^{+} \mathrm{CD} 11 \mathrm{~b}^{+} \mathrm{Gr} 1^{+}$cells at 7 days in liquid culture. (C) The frequency of $\mathrm{Kit}^{+} \mathrm{CD} 11 \mathrm{~b}^{-}$ $\mathrm{Gr}^{-}$and $\mathrm{Kit}^{+} \mathrm{CD} 1 \mathrm{~b}^{+} \mathrm{Gr}^{+}$cells in the liquid culture $\left({ }^{* *} \mathrm{p}<0.01,{ }^{* * *} \mathrm{p}<0.001, \mathrm{n}=2\right)$. (D) Serial replating studies. CFUs were quantified by methylcellulose culture using WT and Necdin null fetal liver cells. The methylcellulose cultures were serially replated, weekly, for 4 weeks. Mean values $\left( \pm \mathrm{SD}\right.$ ) were shown $\left({ }^{* *} \mathrm{p}<0.01, \mathrm{n}=3\right)$. (E) Necdin null fetal liver cells expressing MLL-AF9 show enhanced replating potential compared to WT cells ( ${ }^{*} \mathrm{p}<0.05,{ }^{* *} \mathrm{p}<0.01, \mathrm{n}=3$ ). (F) and (G) Liquid culture of WT and Necdin null fetal liver cells expressing MLL-AF9. 48 (F) and $72(\mathrm{G})$ hours later, cell proliferation was determined by cell counting. Cell growth was presented relative to the number of input cells in each group, set as $1\left({ }^{*} \mathrm{p}<0.05,{ }^{* *} \mathrm{p}<0.01, \mathrm{n}=3\right)$. 
leukemia cell survival. The number of total apoptotic cells was comparable between two groups following 24 hour AraC treatment (Figure 3C). While loss of Necdin did not affect the early apoptosis of leukemia cells expressing MLL-AF9 following 48 hour AraC treatment (Figure 3D), the number of late apoptotic cells $\left(\right.$ Annexin $\mathrm{V}^{+} / \mathrm{PI}^{+}$) was significantly increased in Necdin null group compared with wild type group following high concentration of $\operatorname{AraC}(0.5 \mu \mathrm{M})$ treatment (Figure 3E). We then performed cell cycle analysis of leukemia cells treated with DMSO
A

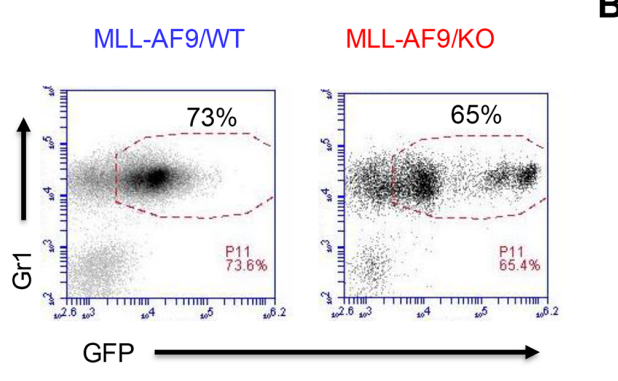

C

D

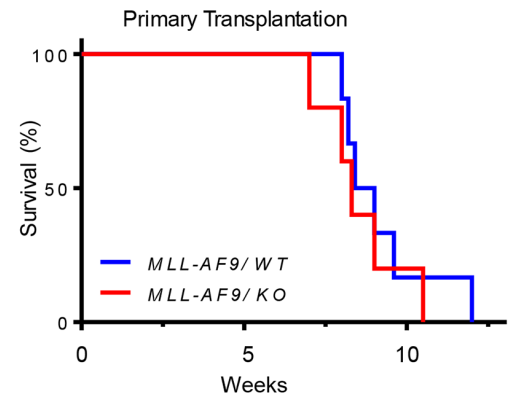

B
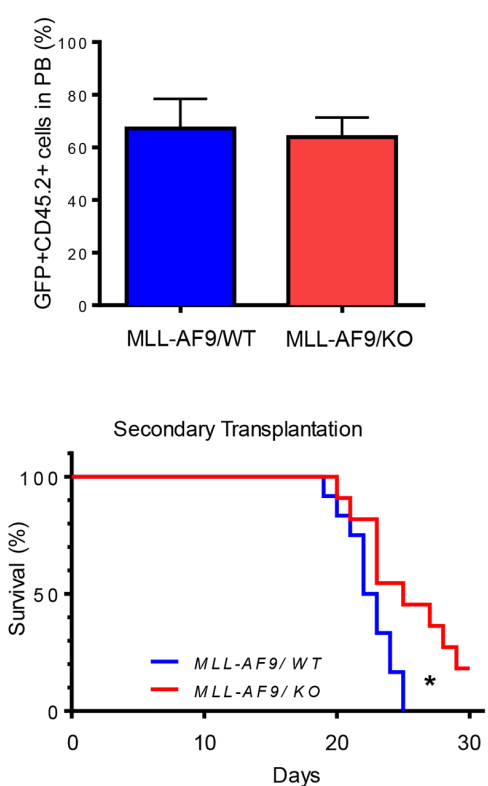

E

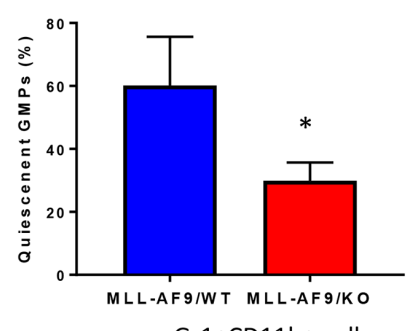

F

cKit+ cells

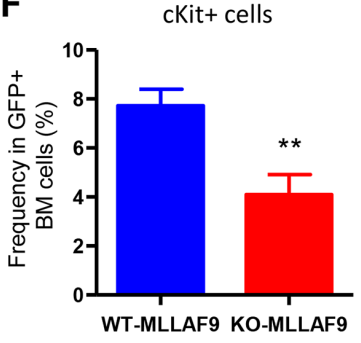

H
G

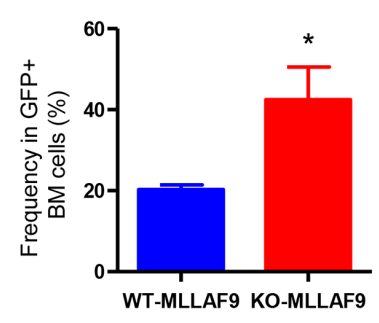

GMPs
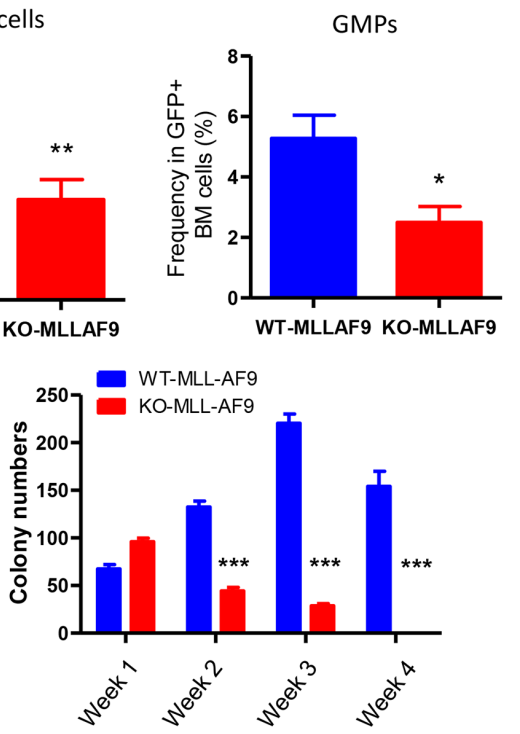

Figure 2: Necdin deficiency delays the progression of leukemia-induced by MLL-AF9. (A) Primary transplantation of fetal liver cells expressing MLL-AF9. Representative flow cytometry plots show the frequency of $\mathrm{GFP}^{+} \mathrm{Gr}^{+}$cells in the peripheral blood of recipient mice 4 weeks following transplantation. (B) The frequency of donor-derived cells $\left(\mathrm{CD} 45.2^{+} \mathrm{GFP}^{+}\right)$in the peripheral blood $(\mathrm{PB})$ of recipient mice was determined by flow cytometry analysis $(\mathrm{p}=0.2, \mathrm{n}=5)$. (C) Survival curve of animals transplanted with wild type or Necdin null fetal liver cells expressing MLL-AF9 $(p=0.2, n=5)$. (D) Bone marrow cells isolated from primary recipient mice were transplanted into lethally irradiated recipient mice. Survival curve of recipient mice transplanted with WT or Necdin null leukemia cells expressing MLL-AF9 ( $\left.{ }^{*} \mathrm{p}<0.05, \mathrm{n}=7\right)$. (E) The quiescence of GMPs in the BM of leukemia mice were determined by Ki67 and DAPI staining. Quiescent cells are defined as Ki67 cells $\left({ }^{*} \mathrm{p}<0.05, \mathrm{n}=3\right)$. (F) The frequency of $\mathrm{Kit}^{+}$cells and GMPs in the BM of leukemia mice was determined by flow cytometry analysis $\left({ }^{*} \mathrm{p}<0.05,{ }^{* *} \mathrm{p}<0.01, \mathrm{n}=5\right)$. (G) The frequency of myeloid cells $\left(\mathrm{Gr} 1^{+} \mathrm{CD} 11 \mathrm{~b}^{+}\right)$in the $\mathrm{BM}$ of leukemia mice was determined by flow cytometry analysis $\left({ }^{*} \mathrm{p}<0.05, \mathrm{n}=5\right)$. (H) Necdin null GMPs expressing MLL-AF9 show decreased replating potential compared to wild type leukemia cells $\left({ }^{* * *} \mathrm{p}<0.001, \mathrm{n}=3\right)$. 
or AraC $(0.2 \mu \mathrm{M})$. While AraC treatment did not affect the cell cycle status of wild type leukemia cells expressing MLL-AF9, AraC treatment increased the number of Necdin null leukemia cells in the G0/G1 phase of the cell cycle and decreased the number of Necdin null leukemia cells in the $\mathrm{S}$ phase of the cell cycle (Figure 3F).

To understand the molecular basis of enhanced apoptosis and cell cycle arrest seen in the Necdin null leukemia cells following $\mathrm{AraC}$ treatment, we examined the expression of genes that regulate apoptosis and cell cycle, including Bcl2, Bax and p53, in leukemia cells treated with DMSO or AraC. We observed decreased levels of Bcl2 and increased levels of p53 and its target gene Bax in Necdin null leukemia cells compared to wild type leukemia cells following AraC treatment (Figure $3 \mathrm{G})$. While $\mathrm{Bcl} 2$ inhibits apoptosis, Bax promotes p53dependent apoptosis following genotoxic stress [31-32]. These findings suggest that Necdin deficiency may activate the p53-dependent apoptotic pathways in MLL$\mathrm{AF}^{+}$leukemia cells following AraC treatment.

\section{Necdin deficiency decreases the proliferation of hematopoietic progenitor cells expressing AML1- ETO9a}

In addition to MLL-AF9-induced leukemia, we also utilized a mouse model of human AML induced by the AML-ETO9a oncogene to determine the role of Necdin in leuekmia initiation and progression [16]. We infected wild type and Necdin null HSPCs with retroviruses expressing GFP or AML1-ETO9a. Robust expression of GFP was seen $72 \mathrm{~h}$ post-infection (Figure $4 \mathrm{~A}$ ). We then cultured transduced cells $\left(\mathrm{GFP}^{+}\right)$in serum free medium in the presence of cytokines for seven days and then examined the frequency of HSPCs. We found comparable numbers of $\mathrm{Kit}^{+} \mathrm{CD} 11 \mathrm{~b}^{-} \mathrm{Gr} 1^{-}$and $\mathrm{Kit}^{+} \mathrm{CD} 11 \mathrm{~b}^{+} \mathrm{Gr} 1^{+}$cells in both wild type and Necdin null cell cultures (Figures 4B and 4C). We performed serial replating assays using wild type and Necdin null HSPCs expressing AML-ETO9a. While Necdin null HSPCs show decreased colony formation in week one compared to that of the WT cells, these cells show enhanced colony formation than that of the wild type cells by week 4 (Figure 4D). We then examine the effect of Necdin deficiency on HSPC proliferation and found that Necdin null HSPCs expressing AML1-ETO9a show decreased proliferation compared to wild type HSPCs (Figures 4E and 4F), indicating that Necdin is important for the proliferation of HSPCs expressing AML-ETO9a.

\section{Necdin deficiency decreases the repopulating potential of hematopoietic stem and progenitor cells expressing AML1-ETO9a}

To determine the role of Necdin in AML-ETO9a -induced leukemia, we transplanted 100,000 wild type or Necdin null HSPCs expressing AML-ETO9a
$\left(\mathrm{CD} 45.2^{+} \mathrm{GFP}^{+}\right)$into lethally irradiated recipient mice (B6.SJL mice, CD45.1 $1^{+}$) together with 100,000 normal competitor cells $\left(\mathrm{CD} 45.1^{+}\right)$. In primary transplantation, we observed no difference in the frequency of donor-derived $\mathrm{GFP}^{+}$cells in mice repopulated with wild type or Necdin null HSPCs expressing AML-ETO9a at 8 weeks following transplantation (Figure 5A). There is no apparent effect of Necdin deficiency on the survival of recipient mice as most recipient mice transplanted with wild type or Necdin null mice are still alive 14 weeks following transplantation (Figure 5B), suggesting the Necdin may be dispensable for AML1-ETO9a-mediated leukemia initiation.

To determine the impact of Necdin deficiency on the repopulating potential of hematopoietic stem and progenitor cells expressing AML1-ETO9a, we sacrificed the primary recipient mice 16 weeks following transplantation and harvested $\mathrm{GFP}^{+}$bone marrow cells for secondary transplantation. We performed Limitingdilution transplantation assays by transplanting $3 \times 10^{5}$ or $3 \times 10^{6} \mathrm{AML1}^{-\mathrm{ETO}^{+}}$bone marrow cells (CD45.2 ${ }^{+}$ $\mathrm{GFP}^{+}$) isolated from the primary recipient mice into lethally irradiated recipient mice (B6.SJL, CD45.1). We monitored engraftment of $\mathrm{GFP}^{+}$hematopoietic cells in peripheral blood by flow cytometry every 4 weeks after transplantation. We found that Necdin null bone marrow cells show decreased engraftment using both concentrations of donor cells 16 weeks post transplantation (Figures 5C and 5D), suggesting that loss of Necdin decreases the repopulating potential of hematopoietic stem and progenitor cells expressing AML1-ETO9a.

To determine the impact of Necdin deficiency on hematopoietic stem and progenitor cells in vivo, we analyzed the bone marrow of secondary recipient mice repopulated with wild type or Necdin null bone marrow cells expressing AML1-ETO9a. We observed comparable number of donor-derived (CD45.2 $2^{+} \mathrm{GFP}^{+}$) myeloid cells

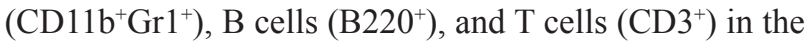
bone marrow of recipient mice from both the wild type and the Necdin null groups (Figure 5E), indicating that Necdin deficiency does not affect terminal differentiation of HSPCs expressing AML1-ETO9a. In addition, we found comparable numbers of donor-derived (CD45.2 $\mathrm{GFP}^{+}$) hematopoietic progenitor cells ( $\mathrm{Lin}^{-\mathrm{Sca}}{ }^{-} \mathrm{Kit}^{+}$and $\mathrm{Lin}^{-}$ $\left.\mathrm{Sca}^{+} \mathrm{Kit}^{+}\right)$in the bone marrow of recipient mice from both groups, suggesting that Necdin deficiency does not alter the frequency HSPCs expressing AML1-ETO9a in vivo (Figure 5F).

\section{The impact of AraC treatment on hematopoietic cells expressing AML1-ETO9a}

Given that loss of Necdin decreases the proliferation of hematopoietic progenitor cells expressing AML1ETO9a (Figure 4E and 4F), we predicted that Necdindeficient hematopoietic cells expressing AML1-ETO9a would not be sensitive to chemotherapy. We isolated 
A

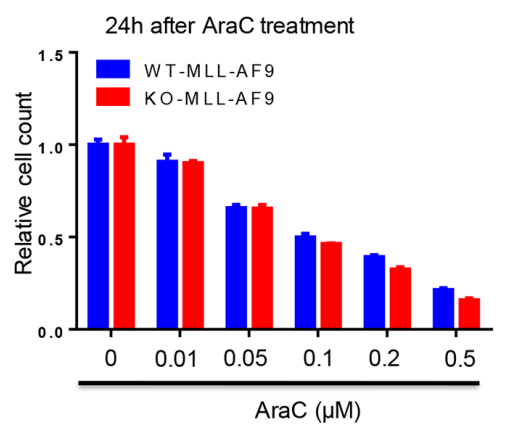

C

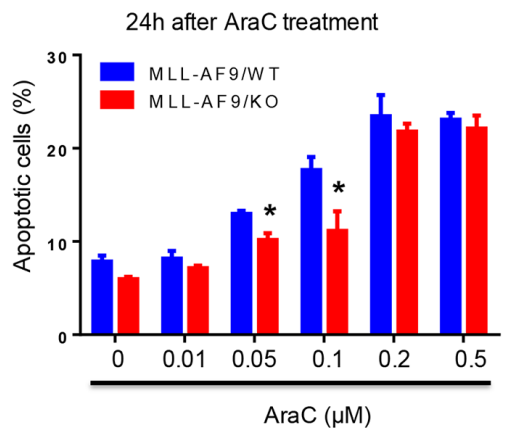

E

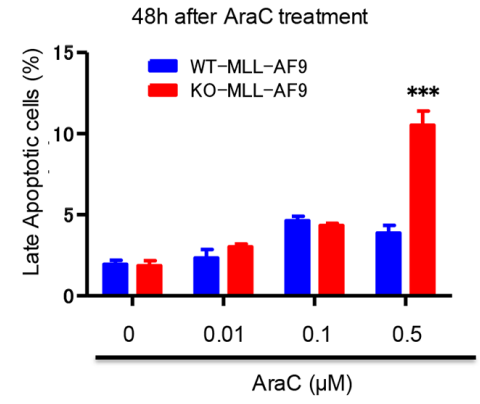

B

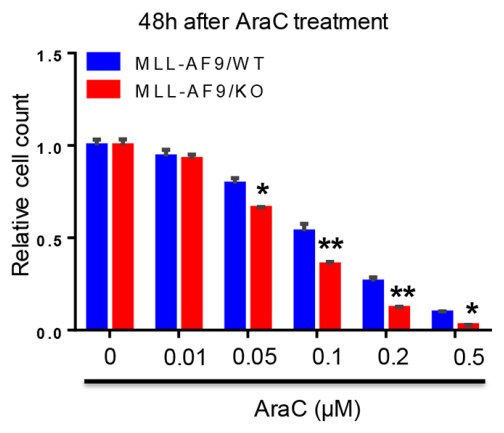

D

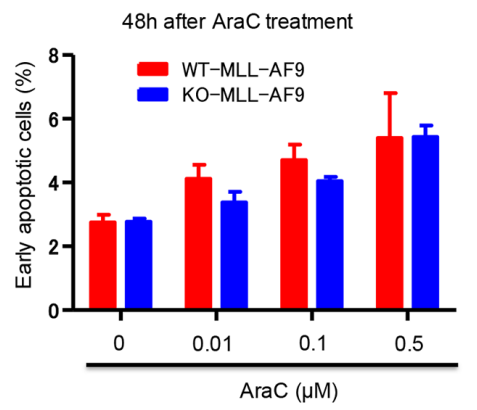

$\mathbf{F}$

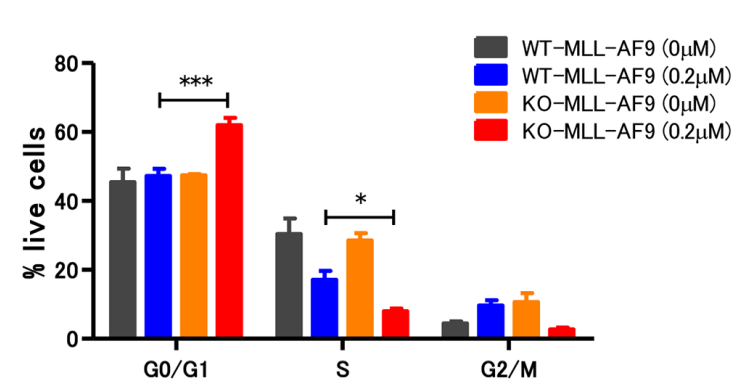

Bax

p53
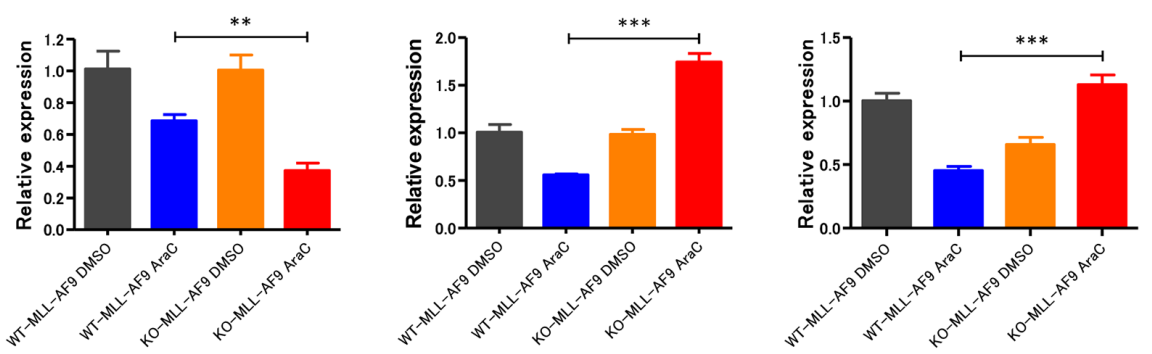

Figure 3: Necdin null leukemia cells expressing MLL-AF9 are sensitive to chemotherapy treatment. (A) and (B) WT and Necdin null leukemia cells expressing MLL-AF9 were treated with DMSO or different concentrations of chemotherapy drug cytarabine (AraC). 24 (A) and 48 (B) hours after AraC treatment, the viability of treated leukemia cells was measured by cell counting (* $\mathrm{p}<0.05$, ${ }^{* *} \mathrm{p}<0.01, \mathrm{n}=3$ ). (C) WT and Necdin null leukemia cells expressing MLL-AF9 were treated with DMSO or different concentrations of AraC. 24 hours after AraC treatment, the frequency of total apoptotic cells (Annexin $\mathrm{V}^{+}$) was determined by flow cytometry analysis ( $\mathrm{p}<0.05, \mathrm{n}=3$ ). (D) and (E) WT and Necdin null leukemia cells expressing MLL-AF9 were treated with DMSO or different concentrations of AraC. 48 hours after AraC treatment, the frequency of early apoptotic cells (Annexin $\mathrm{V}^{+} \mathrm{PI}$ ) and late apoptotic cells $\left(\right.$ Annexin $\mathrm{V}^{+} \mathrm{PI}^{+}$) was determined by flow cytometry analysis $\left({ }^{* * *} \mathrm{p}<0.001, \mathrm{n}=3\right.$ ). (F) Wild type and Necdin null leukemia cells were treated with DMSO or AraC $(0.2 \mu \mathrm{M}) .24$ hours later, cell cycle status of leukemia cells was determined by flow cytometry analysis $\left({ }^{*} \mathrm{p}<0.05,{ }^{* * *} \mathrm{p}<0.001, \mathrm{n}=3\right)$. (G) Wild type and Necdin null leukemia cells were treated with DMSO or AraC. 6 hours later, the expression of $B c l 2, B a x$, and $p 53$ in leukemia cells was determined by quantitative real-time PCR analysis $\left({ }^{* *} \mathrm{p}<0.01,{ }^{* *} \mathrm{p}<0.001, \mathrm{n}=3\right)$. 
A

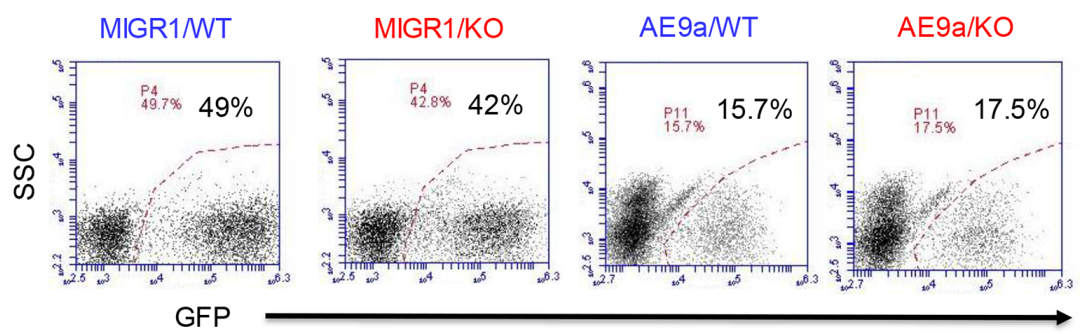

B
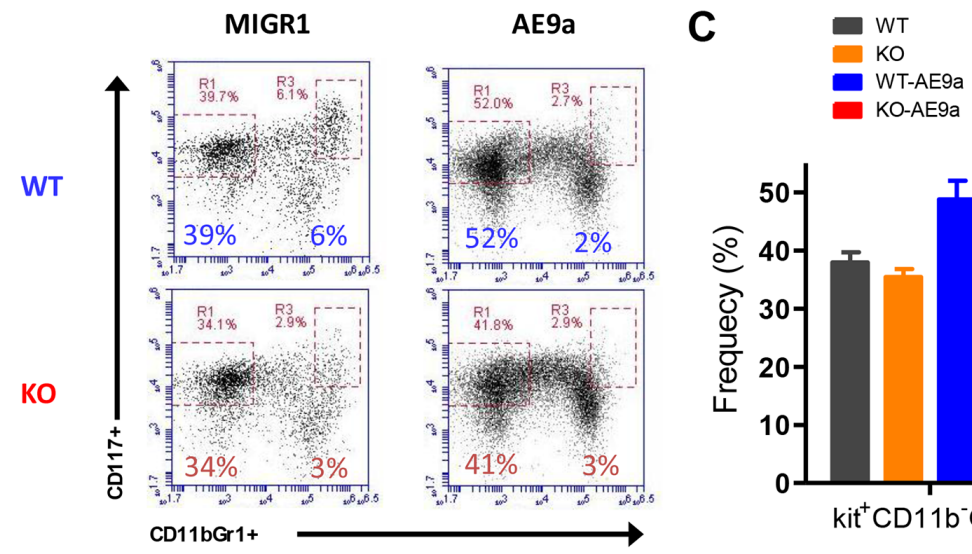

D

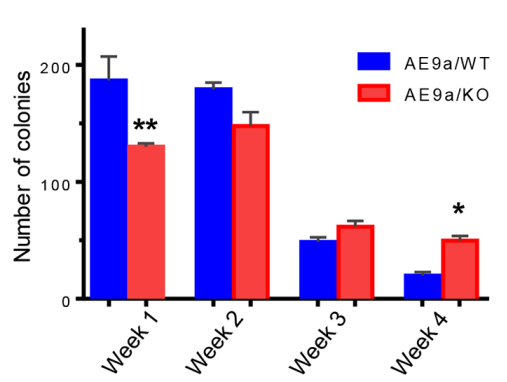

E
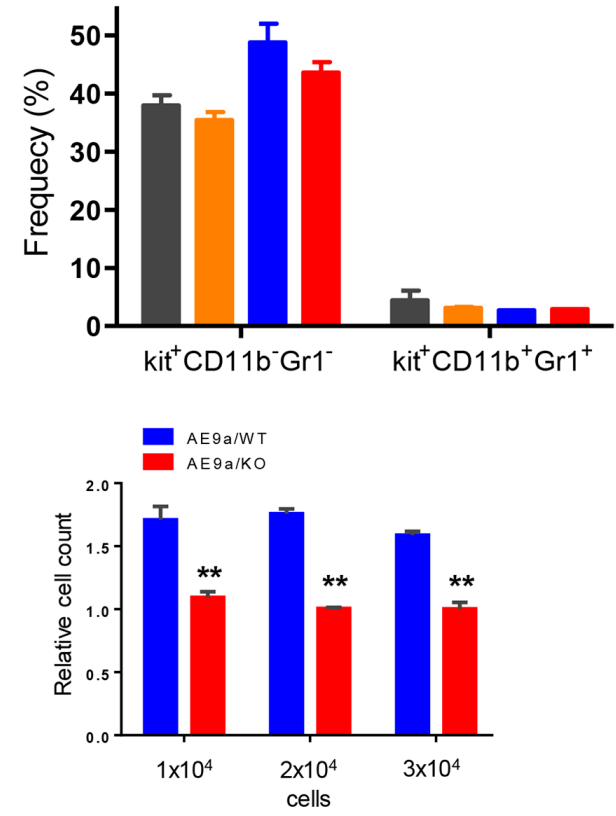

$\mathbf{F}$

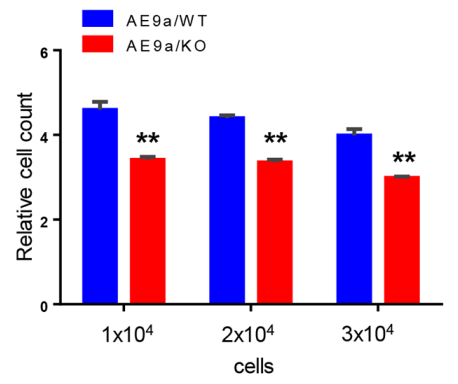

Figure 4: Necdin deficiency decreases the proliferation of hematopoietic progenitor cells expressing AML1-ETO9a. (A) Fetal liver cells isolated from wild-type (WT) or Necdin knock-out (KO) mice were transduced with retroviruses expressing GFP (MIGR1) or AML1-ETO9a. Representative flow cytometry plots show the frequency of transduced cells $\left(\mathrm{GFP}^{+}\right) 72$ hours following transduction. (B) Transduced wild type and Necdin null fetal liver cells $\left(\mathrm{GFP}^{+}\right)$were cultured in serum free medium in the presence of cytokines for seven days. The frequency of hematopoietic stem and progenitor cells was determined by flow cytometry analysis. Representative flow cytometry plots show the frequency of $\mathrm{Kit}^{+} \mathrm{CD} 11 \mathrm{~b}-\mathrm{Gr}^{-}$and $\mathrm{Kit}^{+} \mathrm{CD} 11 \mathrm{~b}^{+} \mathrm{Gr} 1^{+}$cells at 7 days in liquid culture. (C) The frequency of Kit ${ }^{+} \mathrm{CD} 11 \mathrm{~b}-\mathrm{Gr} 1^{-}$ and $\mathrm{Kit}^{+} \mathrm{CD} 11 \mathrm{~b}^{+} \mathrm{Gr}^{+}$cells in the liquid culture $(\mathrm{p}<0.2, \mathrm{n}=2)$. (D) Necdin null fetal liver cells expressing AML1-ETO9a show enhanced replating potential compared to WT cells ( ${ }^{*} \mathrm{p}<0.05,{ }^{* *} \mathrm{p}<0.01, \mathrm{n}=3$ ). (E) Liquid culture of WT and Necdin null fetal liver cells expressing AML1-ETO9a. Cell proliferation at 48 hours was determined by cell counting. Cell growth was presented relative to the number of input cells in each group, set as $1\left({ }^{* *} \mathrm{p}<0.01, \mathrm{n}=3\right)$. (F) Liquid culture of WT and Necdin null fetal liver cells expressing AML1-ETO9a. Cell proliferation at 72 hours was determined by cell counting. Cell growth was presented relative to the number of input cells in each group, set as $1\left({ }^{* *} \mathrm{p}<0.01, \mathrm{n}=3\right)$. 
A

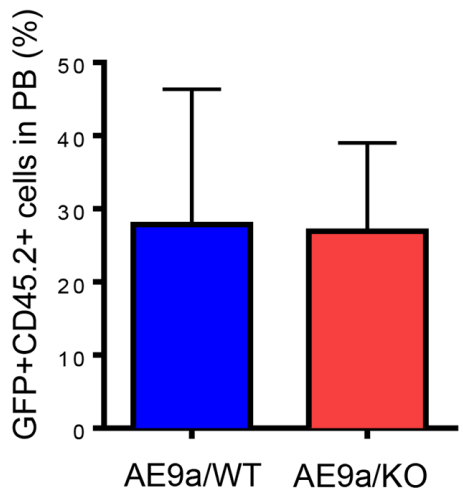

C

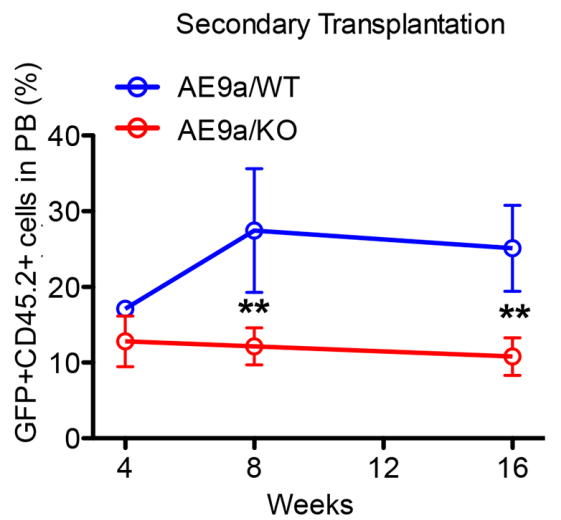

$\mathbf{E}$
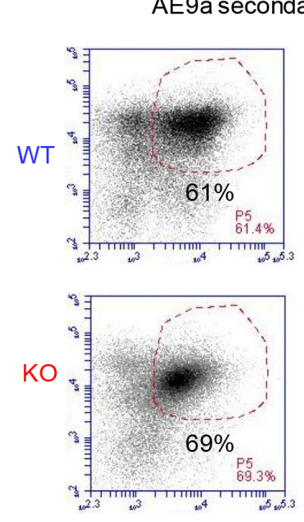

GFP
B

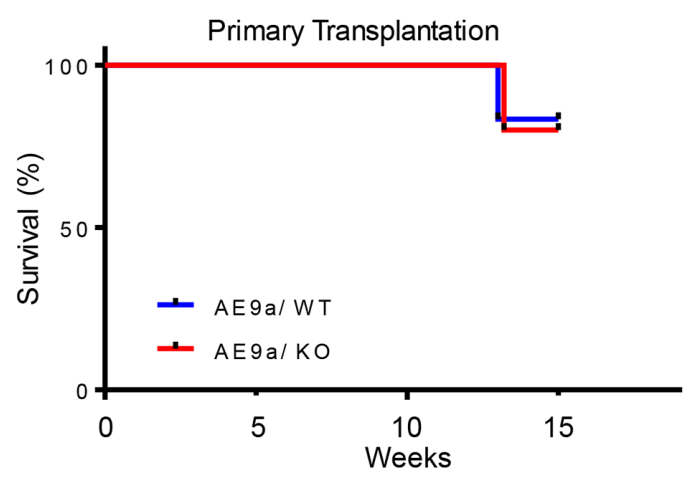

D

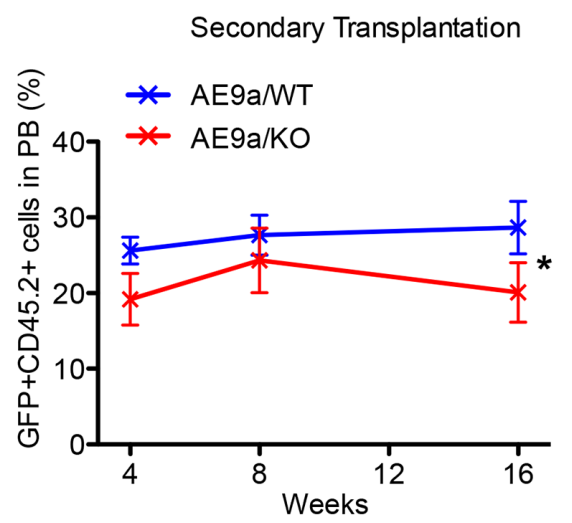

$\mathbf{F}$

GFP+Lin- Gated

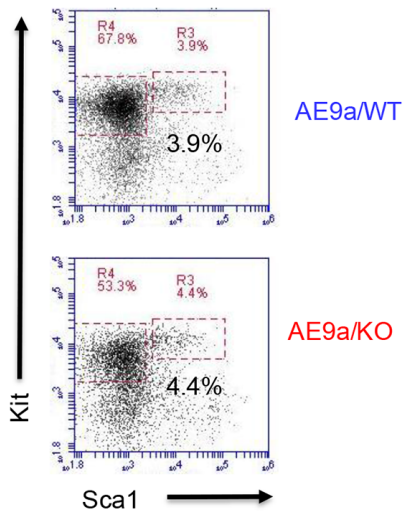

Figure 5: Necdin deficiency decreases the repopulating potential of hematopoietic stem and progenitor cells expressing AML1-ETO9a. (A) Primary transplantation of fetal liver cells expressing AML1-ETO9a. The frequency of donor-derived cells $\left(\mathrm{CD} 45.2^{+} \mathrm{GFP}^{+}\right)$in the peripheral blood $(\mathrm{PB})$ of recipient mice at 8 weeks following transplantation was determined by flow cytometry analysis $(\mathrm{p}=0.2, \mathrm{n}=5-6)$. (B) Survival curve of animals transplanted with WT or Necdin null fetal liver cells expressing AML1-ETO9a $(\mathrm{P}=0.2, \mathrm{n}=5-6)$. (C) and (D) Secondary transplantation assays using $3 \times 10^{5}(\mathrm{C})$ or $3 \times 10^{6}(\mathrm{D})$ bone marrow cells from mice repopulated with WT or Necdin null fetal liver cell expressing AML1-ETO9a. The frequency of donor-derived cells $\left(\mathrm{CD} 45.2^{+} \mathrm{GFP}^{+}\right)$in peripheral blood was measured by flow cytometry analysis every four weeks for 16 weeks. ( $\left.\mathrm{p}<0.05,{ }^{* *} \mathrm{p}<0.01, \mathrm{n}=5\right)$. (E) The frequency of donor-derived $\left(\mathrm{CD} 45.2^{+} \mathrm{GFP}^{+}\right)$myeloid cells $\left(\mathrm{CD} 11 \mathrm{~b}^{+} \mathrm{Gr}^{+}\right)$, B cells $\left(\mathrm{B} 220^{+}\right)$, and $\mathrm{T}$ cells $\left(\mathrm{CD}^{+}\right)$in the bone marrow of secondary recipient mice at 16 weeks following transplantation was determined by flow cytometry analysis. (F) The frequency of donor-derived $\left(\mathrm{CD} 45.2^{+} \mathrm{GFP}^{+}\right) \mathrm{Lin}^{-S c a} 1^{-}$ $\mathrm{Kit}^{+}$and $\mathrm{Lin}^{-} \mathrm{Sca}^{+} \mathrm{Kit}^{+}$cells in the bone marrow of secondary recipient mice at 16 weeks following transplantation was determined by flow cytometry analysis. 
wild type and Necdin null hematopoietic cells from the secondary recipient mice repopulated with hematopoietic cells expressing AML1-ETO9a. We treated wild type and Necdin null cells with DMSO or different concentrations of chemotherapy drug cytarabine (AraC) and monitored cell viability by cell counting. We found that the viability of wild type and Necdin null hematopoietic cells expressing AML1-ETO9a were comparable following AraC treatment (Figures 6A, 6B and 6C). The LC50 for AraC on wild type cells is $0.15 \mu \mathrm{M}$ and the LC50 for AraC on Necdin-deficient cells expressing AML1-ETO9a is $0.14 \mu \mathrm{M}$. We then examined the impact of AraC treatment on the survival of hematopoietic cells expressing AML1ETO9a. While loss of Necdin did not affect the number of early apoptotic (Annexin $\mathrm{V}^{+} / \mathrm{PI}^{-}$) leukemia cells expressing AML1-ETO9a (Figure 6D), the number of late apoptotic cells (Annexin $\mathrm{V}^{+} / \mathrm{PI}^{+}$) was significantly increased in Necdin null group compared with wild type group following high concentration of AraC treatment (Figure $6 \mathrm{E})$. We also examined the apoptosis of hematopoietic cells 72 hours after AraC treatment. Although the number of early apoptotic cells was comparable in both groups (Figure 6F), the number of late apoptotic cells was decreased in the Necdin null group compared to wild type group (Figure 6G).

\section{DISCUSSION}

Many cancers seem to depend on a small population of 'cancer stem cells' for their continued growth and propagation [2]. The leukemia-initiating cell (LIC) or leukemia stem cell (LSC) was the first such cell to be described [2-3]. Leukemia-initiating cells (LICs), particularly those that are in a quiescent state, are resistant to chemotherapy or targeted therapies [5-7]. The LIC is likely to be the most crucial target in the treatment of leukemia, and a thorough understanding of its biology particularly how the LIC differs from the HSC - might allow it to be selectively targeted, improving therapeutic outcome $[2,8]$. However, the critical regulators of LIC quiescence are largely unknown [9-10]. Thus, deciphering the molecular mechanisms controlling LIC quiescence is essential for developing therapeutic strategies that can eliminate quiescent LICs.

Quiescence (G0) is a physiological state occupied by "resting" cells that have exited the cell cycle [9]. It was generally thought that the HSC pool turn over every few weeks [33-34]. However, recent findings suggest that there are dormant HSCs and activated HSCs in laboratory animals [35]. Dormant HSCs are efficiently activated in response to bone marrow injury or G-CSF stimulation. However, once the steady state is reestablished, the activated HSCs return to dormancy, suggesting that HSCs reversibly switch from dormancy to self-renewal during homeostasis and repair [35]. Both HSC-intrinsic regulators and bone marrow niche factors contribute to HSC quiescence [9]. Cell cycle regulators, such as PTEN, Rb, PML, and MEF, regulate hematopoietic stem cell quiescence [36-40]. Stem cell niche signals, such as Angiopoietin/Tie2 signaling, promote HSC quiescence [41].

We demonstrated that p53 plays a critical role in regulating HSC quiescence and identified Necdin as an important p53 target gene in HSCs [20]. To determine the role of Necdin in hematopoiesis, we analyzed the hematopoietic compartment of a strain of Necdin-null mice that die perinatally and have features resembling those seen in the human Prader-Willi Syndrome [42]. While Necdin functions like p53 to maintain HSC quiescence during steady state, Necdin opposes p53dependent apoptosis under conditions of genotoxic stress [21]. Despite being a p53 target, Necdin appears to both mimic and antagonize p53 function in hematopoietic stem and progenitor cells [20-21]. Recently, down regulation of p53 target genes, including Necdin and Gfi-1, in hematopoietic stem and progenitor cells, has been shown to promote ENU-induced leukemogenesis [43]. While some patients with Prader-Willi Syndrome develop AML [29], the role of Necdin in leukemogenesis is largely unknown. We utilized two well-established murine models of human AML induced by MLL-AF9 and AML1-ETO9a to determine the role of Necdin in leukemia development and discovered that Necdin controls leukemia-initiating cell quiescence and chemotherapy response in a contextdependent manner.

Murine fetal liver mainly consists of hematopoietic stem and progenitor cells that are highly proliferative [44]. To determine the impact of Necdin on hematopoietic progenitor cell proliferation, we introduced oncogenic fusion proteins, including MLL-AF9 and AML1-ETO9a, into wild type and Necdin null fetal liver cells and performed proliferation assays. While loss of Necdin enhanced the proliferation of fetal liver cells expressing MLL-AF9 (Figures 1F and 1G), Necdin deficiency decreased the proliferation of fetal liver cells expressing AML1-ETO9a (Figures 4E and 4F). Thus, Necdin appears to play distinct roles in regulating the proliferation of hematopoietic progenitor cells expressing different oncogenic fusion proteins. The leukemia-initiating cells in MLL-AF9-induced leukemia are GMPs [13]. We found that Necdin null GMPs expressing MLL-AF9 were less quiescent than wild-type GMPs (Figure 2E), suggesting that Necdin maintains the quiescence of LICs expressing MLL-AF9. Whether Necdin contributes to the quiescence of LICs expressing AML1-ETO9a is not known. Based upon the effect of Necdin deficiency on normal hematopoietic progenitor cells expressing AML1-ETO9a (Figures 4E and 4F), we predict that loss of Necdin may enhance the quiescence of AML1-ETO9a ${ }^{+}$LICs.

In the bone marrow transduction and transplantation model of MLL-AF9, all recipient mice developed AML, with a median latency of 84.5 days [13]. To determine the role of Necdin in MLL-AF9-induced leukemia, we 
A

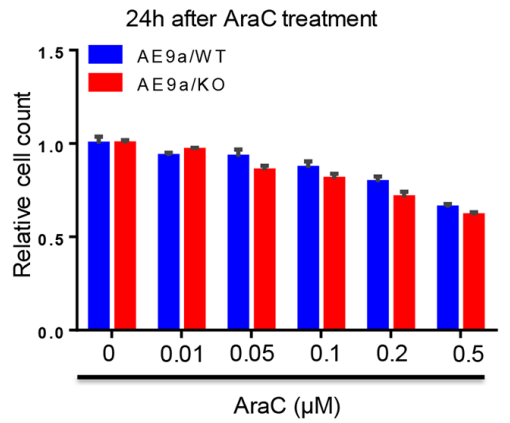

C

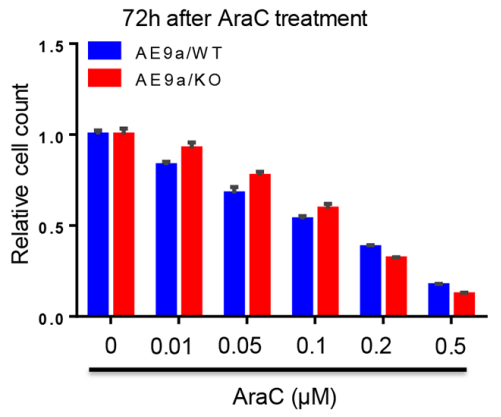

$\mathbf{E}$

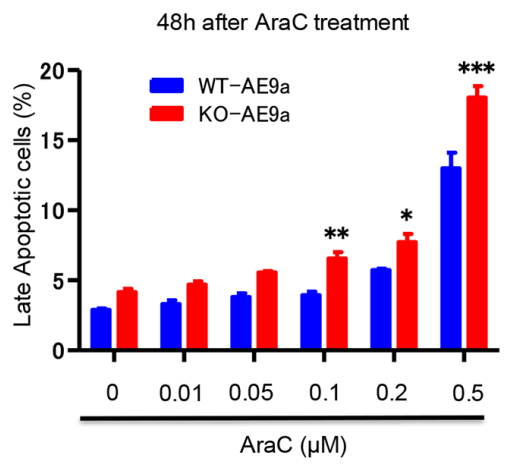

G

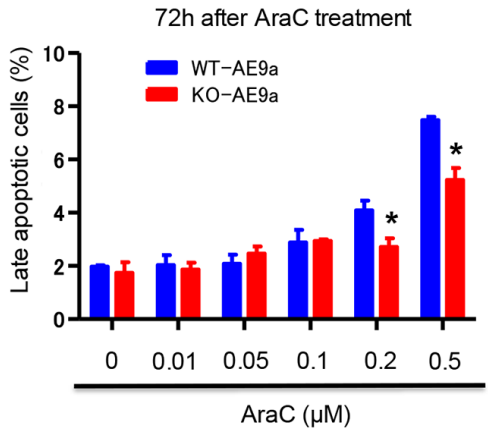

B

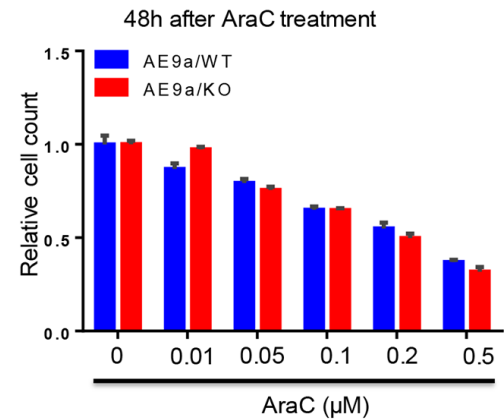

D

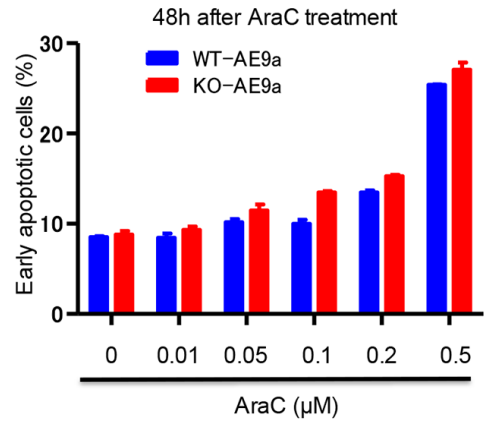

$\mathbf{F}$

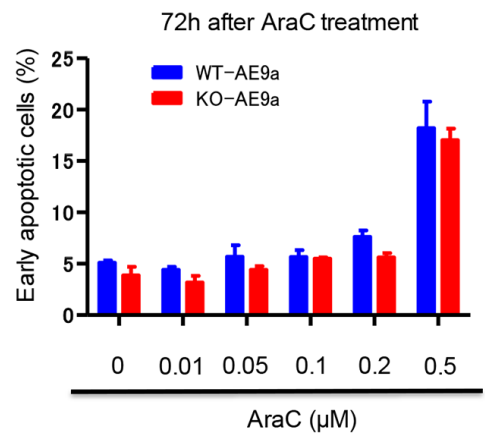

Figure 6: The impact of AraC treatment on hematopoietic cells expressing AML1-ETO9a. (A), (B), and (C) WT and Necdin null hematopoietic cells expressing AML1-ETO9a were treated with DMSO or different concentrations of chemotherapy drug cytarabine (AraC). 24 (A), 48 (B), and 72 (C) hours after AraC treatment, the viability of treated hematopoietic cells was measured by cell counting $(\mathrm{n}=3)$. (D) and (E) WT and Necdin null hematopoietic cells expressing AML1-ETO9a were treated with DMSO or different concentrations of AraC. 48 hours after AraC treatment, the frequency of early apoptotic cells (Annexin $\mathrm{V}^{+} \mathrm{PI}$ ) and late apoptotic cells (Annexin $\mathrm{V}^{+} \mathrm{PI}^{+}$) was determined by flow cytometry analysis $\left({ }^{*} \mathrm{p}<0.05,{ }^{* *} \mathrm{p}<0.01,{ }^{* * *} \mathrm{p}<0.001, \mathrm{n}=3\right)$. (F) and (G) WT and Necdin null hematopoietic cells expressing AML1-ETO9a were treated with DMSO or different concentrations of AraC. 72 hours after AraC treatment, the frequency of early apoptotic cells (Annexin $\mathrm{V}^{+} \mathrm{PI}$ ) and late apoptotic cells (Annexin $\mathrm{V}^{+} \mathrm{PI}^{+}$) was determined by flow cytometry analysis ( ${ }^{*} \mathrm{p}<0.05, \mathrm{n}=3$ ). 
introduced MLL-AF9 into wild type and Necdin null fetal livers cells and performed transplantation assays. In primary transplantation assays, the survival rate between wild type and Necdin null groups was comparable (Figure 2C); However, Necdin deficiency significantly delayed the development of leukemia induced by MLLAF9 in secondary transplantation assays (Figure 2D). These findings suggest that Necdin may be important for the progression but not the initiation of leukemia induced by MLL-AF9. To understand the mechanisms by which Necdin deficiency delays leukemia onset, we characterized the behavior of GMPs in the bone marrow of the secondary recipient mice. We found that loss of Necdin decreased the number of GMPs in the bone marrow of recipient mice (Figure 2F). Further, Necdin null GMPs show decreased replating capability compared to wild-type GMPs (Figure 2H). These findings indicate that Necdin deficiency decreases both the number and the function of GMPs expressing MLL-AF9. In addition, we found increased number of myeloid cells in the bone marrow of recipient mice repopulated with Necdin null bone marrow cells compared to that of the wild-type cells (Figure 2G). Thus, the delayed leukemia development seen in the recipient mice repopulated with Necdin null bone marrow cells expressing MLL-AF9 may be due to decreased number of GMPs as well as enhanced myeloid differentiation.

While AML1-ETO is insufficient to cause acute leukemia by itself in human or mouse cells [14-15], AML1-ETO9a fusion protein is sufficient to cause leukemia in mice [16-17]. To determine the role of Necdin in AML1-ETO9a-induced leukemia, we introduced AML1-ETO9a into wild type and Necdin null fetal livers cells and performed transplantation assays. Sixteen weeks following primary transplantation assays, all recipient mice were still alive (Figure 4B). Given that hematopoietic progenitor cells expressing AML1-ETO9a show enhanced replating potential in vitro (Figure 4D), we predicted that loss of Necdin would increase the repopulating potential of bone marrow cells expressing AML1-ETO9a in vivo. To test this, we isolated bone marrow cells from primary recipient mice repopulated with wild type and Necdin null fetal liver cells and performed secondary transplantation assays with limiting dilution of donor bone marrow cells. Surprisingly, loss of Necdin decreased the number of donor-derived cells in the peripheral blood of secondary recipient mice 16 weeks post transplantation (Figures $5 \mathrm{C}$ and 5D), suggesting that Necdin deficiency may decrease the repopulating potential of AML1-ETO9a ${ }^{+}$ hematopoietic stem and progenitor cells in transplantation assays. We only monitored the survival of secondary recipient mice for 16 weeks and all mice were alive at the time of sacrifice. Given that Necdin deficiency did not affect the number of hematopoietic stem and progenitor cells and their differentiation in the bone marrow (Figures $5 \mathrm{E}$ and $5 \mathrm{~F}$ ), we predict that the survival rate would be comparable between wild type and Necdin null groups in secondary transplantation.

Despite advances in the treatment of acute myeloid leukemia (AML), relapse and drug resistance frequently occur [1]. As Necdin null HSCs are less quiescent than wild-type HSCs and wild type mice repopulated with Necdin null HSCs show enhanced sensitivity to weekly 5-FU treatments or sub-lethal doses of irradiation [21], targeting Necdin may provide a therapeutic approach to eliminating quiescent leukemia-initiating cells. Given that quiescent LICs are resistant to chemotherapy treatment [5-9], we predicted that decreased GMP quiescence would sensitize Necdin-deficient leukemia cells expressing MLL-AF9 to AraC treatment. Indeed, we found that Necdin deficiency enhanced the response of leukemia cells expressing MLL-AF9 to chemotherapy treatment, manifested by decreased viability and enhanced apoptosis (Figures $3 \mathrm{~B}$ and $3 \mathrm{E}$ ). To understand the mechanisms by which Necdin controls chemo-sensitivity, we examined the expression of $\mathrm{p} 53$ and apoptosis related genes in leukemia cells treated with DMSO or AraC. We found that the mRNA levels of $p 53$ and its target gene Bax were increased in Necdin null leukemia cells expressing MLLAF9 compared to wild-type leukemia cells (Figure 3G). However, the expression of apoptosis regulatory gene $\mathrm{Bcl} 2$ was decreased in Necdin null leukemia cells compared to wild-type leukemia cells (Figure 3G). Necdin physically interacts with $\mathrm{p} 53$ and suppresses p53-dependent apoptosis in neurons and hematopoietic cells [21, 25, and 45]. These data suggest that $\mathrm{p} 53$-dependent apoptotic pathways may be activated in Necdin null leukemia cells expressing MLL-AF9 following AraC treatment. Interestingly, AraC treatment induced cell cycle arrest in Necdin null leukemia cells expressing MLL-AF9 (Figure 3F). The cell cycle arrest may be due to increased expression of p53 in Necdin null cells following AraC treatment (Figure $3 \mathrm{G})$. Thus, Necdin deficiency may sensitize leukemia cells expressing MLL-AF9 to AraC treatment through decreasing LIC quiescence and inducing p53-dependent apoptosis and cell cycle arrest.

In contrary to the effect of Necdin deficiency on the response of leukemia cells expressing MLL-AF9 to AraC treatment, loss of Necdin did not affect the viability of leukemia cells expressing AML1-ETO9a following chemotherapy treatment (Figures 6A, 6B and 6C). While Necdin null leukemia cells expressing AML1-ETO9a show enhanced apoptosis at 48 hours after high concentration of AraC treatment (Figure 6E), these cells had decreased apoptosis at 72 hours after AraC treatment (Figure 6G). Given that Necdin null leukemia cells expressing either MLL-AF9 or AML1-ETO9a show enhanced apoptosis at 48 hours after AraC treatment (Figures $3 \mathrm{E}$ and 6E), it is likely that other mechanisms, including senescence, cell cycle arrest, and autophagy, may contribute to the differential response of leukemia cells expressing MLLAF9 or AML1-ETO9a to AraC treatment. 
The leukemia stem cells in AML1-ETO-induced leukemia are HSCs whereas LSCs in MLL-AF9-induced leukemia are GMPs [13, 46-47]. While Necdin is highly expressed in HSCs, the expression of Necdin in progenitor and mature cells is very low $[28,48]$. The reason why Necdin plays very different roles in different types of leukemia may be due to Necdin levels are different between stem cells and progenitor cells. MLL-AF9 and AML1ETO regulates different gene expression signatures to drive leukemia development [12-13, and 47]. In addition, MLL-AF9 and AML1-ETO interact with distinct proteins in hematopoietic stem and progenitor cells [11-12, 19 and 49]. Thus, it is likely that Necdin plays a context dependent role in modulating leukemia-initiating cell quiescence and chemo-sensitivity. The mechanisms by which Necdin modulates leukemia development in response to different oncogenes require further investigation.

In summary, we discovered that Necdin null LICs expressing MLL-AF9 are less quiescent than wild-type LICs and Necdin-deficiency enhanced the response of $\mathrm{MLL}-\mathrm{AF9}^{+}$leukemia cells to chemotherapy treatment. Given that human leukemia patients with MLL-AF9 are resistant to chemotherapy $[1,11]$, our findings suggest that pharmacological inhibition of Necdin may hold potential as a novel therapy for leukemia patients with MLL translocations.

\section{MATERIALS AND METHODS}

\section{Mice}

The generation of Necdin null mice (C57BL/6, CD45.2) was described previously [42]. Fetal liver cells were isolated from E14.5 embryos as previously described [21]. Wild type C57BL/6 (CD45.2) and B6.SJL (CD45.1) mice were purchased from Jackson Laboratories. All mice were maintained in the Indiana University School of Medicine Animal Facility according to IACUC-approved protocols, and kept in Thorensten units with filtered germ-free air.

\section{Transduce fetal liver cells with retrovirus}

Retroviral particles were produced by transfection of Phoenix E cells with the MSCV-MLL-AF9- IRESGFP or MSCV-AML1-ETO9a-IRES-GFP plasmids, according to standard protocols [17]. Murine fetal liver cells were transduced on retronectin (Takara)-coated nontissue culture plates with high-titer retroviral suspensions. Seventy-two hours after infection, GFP-positive cells were sorted by FACS.

\section{Flow cytometry}

Flow cytometry analysis of hematopoietic stem and progenitor cells was performed as described previously [20-21]. Nuclear staining of Ki67 was done by using an FITC-anti-human Ki67 antibody (BD PharMingen) and fixation and permeabilization solutions from BD Biosciences [21]. Flow antibodies were purchased from Biolegend, eBioscience or BD Bioscience. Experiments were performed on FACSAria and FACSLSR II cytometers (BD Biosciences) and analyzed by using the FlowJo Version 9.3.3 software (TreeStar).

\section{Stem and progenitor cell assays}

Clonogenic progenitors were determined in methylcellulose medium (MethoCult GF M3434, StemCell Technologies) using $2 \times 10^{3}$ fetal liver cells per well (6-well plate) [20-21]. Colonies were scored after 7 days of the initial culture, and all cells were collected and washed twice in phosphate-buffered saline. Subsequently cells were cultured at $2 \times 10^{4}$ per well in the same medium. Colony scoring and replating were repeated every 7 days for at least four times, or until no colonies were observed in the cultures.

\section{Transplantation assay}

We transplanted $1 \times 10^{5}$ fetal liver cells from wild type and Necdin null mice (CD45.2 $)$ that expressing MLL-AF9 or AML1-ETO9a into lethally irradiated B6.SJL mice $\left(\mathrm{CD} 45.1^{+}\right)$together with $1 \times 10^{5}$ normal competitor cells $\left(\mathrm{CD} 45.1^{+}\right)$. The presence of $\mathrm{GFP}^{+}$cells in the peripheral blood was measured by flow cytometry analysis every 4 weeks. 16 weeks following primary transplantation, we harvested bone marrow cells from mice reconstituted with wild type or Necdin null fetal liver cells and transplanted $3 \times 10^{6}$ bone marrow cells into lethally irradiated B6.SJL mice (CD45. $\left.1^{+}\right)$.

\section{Chemotherapy treatment}

Leukemia cells expressing MLL-AF9 or AML1ETO9a we treated with DMSO or different concentrations of cytarabine (AraC) for 24 hours, 48 hours and 72 hours, respectively [50]. The proliferation of leukemia cells was determined by FACS analysis. The viability of leukemia cells following AraC treatment was evaluated by PI/ Annexin V staining. Early apoptotic cells were defined as Annexin $\mathrm{V}^{+} \mathrm{PI}^{-}$cells and late apoptotic cells were defined as Annexin $\mathrm{V}^{+} \mathrm{PI}^{+}$cells.

\section{Statistical analysis}

The animal sample size was based on previous studies evaluating the roles of AML1-ETO9a in leukemia and POWER analysis [17]. Gehan-Breslow-Wilcoxon test was used for Kaplan-Meier survival curves. The other data were analyzed by paired or unpaired $t$ test using GraphPad Prizm 6. ${ }^{*}, \mathrm{p}<0.05 ;{ }^{* *}, \mathrm{p}<0.01 ;{ }^{* * *}, \mathrm{p}<0.001$; ns, not significant. All experiments were repeated at least once. 


\section{Author contributions}

CY, MK, and YL designed the research. CY, MK, SC, SCN, RG, and SZL performed the research. CY, $\mathrm{MK}, \mathrm{SC}$, and SCN analyzed the data and performed the statistical analysis. TA provided reagents to the study. CY and $\mathrm{YL}$ wrote the manuscript. All authors read, comment on, and approved the manuscript.

\section{ACKNOWLEDGMENTS}

This work was supported in part by Department of Defense Grant W81XWH-13-1-0187 (YL), a St. Baldrick's Foundation Scholar Award (YL), an Elsa Pardee Foundation New Investigator Award (YL), an Alex's Lemonade Stand Foundation Grant (YL), a Children's Leukemia Research Association Grant (YL), a Leukemia Research Foundation grant (YL), and American Cancer Society Institutional Research Grants (YL). SCN was supported by a NIH/NCI F32 Award (1F32CA203049-01). CY was supported by a Potential Medical Expert's Training Grant of Shanghai University of Traditional Chinese Medicine (Grant Number: 2014.5) and an Excellent Young Physician Program Award of Shanghai Municipal Health Bureau (Grant Number: 2014.118). This work was supported in part by a Project Development Team within the ICTSI NIH/NCRR Grant Number UL1TR001108. The authors acknowledge the Flow Cytometry Core and in vivo Therapeutic Core Laboratories, which are sponsored, in part, by the National Institutes of Health/NIDDK Cooperative Center of Excellence in Hematology (CCEH) grant U54 DK106846. We like to thank Dr. Stephen Nimer at the Sylvester Comprehensive Cancer Center, Miller School of Medicine University of Miami, and Dr. Rachel Wevrick at the University of Alberta for providing reagents to this study. We also like to acknowledge Marilyn Wales for helping the preparation of the manuscript.

\section{CONFLICTS OF INTEREST}

The authors declared that no conflicts of interest exists.

\section{REFERENCES}

1. Roboz GJ. Current treatment of acute myeloid leukemia. Curr Opin Oncol. 2012; 24:711-19.

2. Kreso A, Dick JE. Evolution of the cancer stem cell model. Cell Stem Cell. 2014; 14:275-91.

3. Hope KJ, Jin L, Dick JE. Acute myeloid leukemia originates from a hierarchy of leukemic stem cell classes that differ in self-renewal capacity. Nat Immunol. 2004; 5:738-43.

4. Tenen DG. Disruption of differentiation in human cancer: AML shows the way. Nat Rev Cancer. 2003; 3:89-101.

5. Shlush LI, Zandi S, Mitchell A, Chen WC, Brandwein JM, Gupta V, Kennedy JA, Schimmer AD, Schuh AC, Yee KW,
McLeod JL, Doedens M, Medeiros JJ, et al, and HALT PanLeukemia Gene Panel Consortium. Identification of preleukaemic haematopoietic stem cells in acute leukaemia. Nature. 2014; 506:328-33.

6. Graham SM, Jørgensen HG, Allan E, Pearson C, Alcorn MJ, Richmond L, Holyoake TL. Primitive, quiescent, Philadelphia-positive stem cells from patients with chronic myeloid leukemia are insensitive to STI571 in vitro. Blood. 2002; 99:319-25.

7. Komarova NL, Wodarz D. Effect of cellular quiescence on the success of targeted CML therapy. PLoS One. 2007; 2:e990.

8. Guzman ML, Jordan CT. Considerations for targeting malignant stem cells in leukemia. Cancer Control. 2004; 11:97-104.

9. Trumpp A, Essers M, Wilson A. Awakening dormant haematopoietic stem cells. Nat Rev Immunol. 2010; 10:201-09.

10. Essers MA, Trumpp A. Targeting leukemic stem cells by breaking their dormancy. Mol Oncol. 2010; 4:443-50.

11. Krivtsov AV, Armstrong SA. MLL translocations, histone modifications and leukaemia stem-cell development. Nat Rev Cancer. 2007; 7:823-33.

12. Nimer SD, Moore MA. Effects of the leukemia-associated AML1-ETO protein on hematopoietic stem and progenitor cells. Oncogene. 2004; 23:4249-54.

13. Krivtsov AV, Twomey D, Feng Z, Stubbs MC, Wang Y, Faber J, Levine JE, Wang J, Hahn WC, Gilliland DG, Golub TR, Armstrong SA. Transformation from committed progenitor to leukaemia stem cell initiated by MLL-AF9. Nature. 2006; 442:818-22.

14. Yuan Y, Zhou L, Miyamoto T, Iwasaki H, Harakawa N, Hetherington CJ, Burel SA, Lagasse E, Weissman IL, Akashi K, Zhang DE. AML1-ETO expression is directly involved in the development of acute myeloid leukemia in the presence of additional mutations. Proc Natl Acad Sci USA. 2001; 98:10398-403.

15. Mulloy JC, Cammenga J, MacKenzie KL, Berguido FJ, Moore MA, Nimer SD. The AML1-ETO fusion protein promotes the expansion of human hematopoietic stem cells. Blood. 2002; 99:15-23.

16. Yan M, Kanbe E, Peterson LF, Boyapati A, Miao Y, Wang Y, Chen IM, Chen Z, Rowley JD, Willman CL, Zhang DE. A previously unidentified alternatively spliced isoform of $\mathrm{t}(8 ; 21)$ transcript promotes leukemogenesis. Nat Med. 2006; 12:945-49.

17. Kobayashi M, Chen S, Bai Y, Yao C, Gao R, Sun XJ, Mu C, Twiggs TA, Yu ZH, Boswell HS, Yoder MC, Kapur R, Mulloy JC, et al. Phosphatase PRL2 promotes AML1-ETO-induced acute myeloid leukemia. Leukemia. 2017; 31:1453-57.

18. Sinha C, Cunningham LC, Liu PP. Core Binding Factor Acute Myeloid Leukemia: New Prognostic Categories and Therapeutic Opportunities. Semin Hematol. 2015; $52: 215-22$. 
19. Hatlen MA, Wang L, Nimer SD. AML1-ETO driven acute leukemia: insights into pathogenesis and potential therapeutic approaches. Front Med. 2012; 6:248-62.

20. Liu Y, Elf SE, Miyata Y, Sashida G, Liu Y, Huang G, Di Giandomenico S, Lee JM, Deblasio A, Menendez S, Antipin J, Reva B, Koff A, Nimer SD. p53 regulates hematopoietic stem cell quiescence. Cell Stem Cell. 2009; 4:37-48.

21. Asai T, Liu Y, Di Giandomenico S, Bae N, Xu H, NadiayeLobry D, Deblasio A, Menendez S, Antipin J, Reva B, Wevrick R, Nimer SD. Necdin, a p53 target gene, regulates hematopoietic stem/progenitor cell quiescence and response to genotoxic stress. Blood. 2012; 120:1601-12.

22. Maruyama K, Usami M, Aizawa T, Yoshikawa K. A novel brain-specific mRNA encoding nuclear protein (necdin) expressed in neurally differentiated embryonal carcinoma cells. Biochem Biophys Res Commun. 1991; 178:291-96.

23. Jay P, Rougeulle C, Massacrier A, Moncla A, Mattei MG, Malzac P, Roëckel N, Taviaux S, Lefranc JL, Cau P, Berta P, Lalande M, Muscatelli F. The human necdin gene, NDN, is maternally imprinted and located in the Prader-Willi syndrome chromosomal region. Nat Genet. 1997; 17:357-61.

24. MacDonald HR, Wevrick R. The necdin gene is deleted in Prader-Willi syndrome and is imprinted in human and mouse. Hum Mol Genet. 1997; 6:1873-78.

25. Taniura H, Matsumoto K, Yoshikawa K. Physical and functional interactions of neuronal growth suppressor necdin with p53. J Biol Chem. 1999; 274:16242-48.

26. Taniura H, Taniguchi N, Hara M, Yoshikawa K. Necdin, a postmitotic neuron-specific growth suppressor, interacts with viral transforming proteins and cellular transcription factor E2F1. J Biol Chem. 1998; 273:720-28.

27. Taniura H, Kobayashi M, Yoshikawa K. Functional domains of necdin for protein-protein interaction, nuclear matrix targeting, and cell growth suppression. J Cell Biochem. 2005; 94:804-15.

28. Forsberg EC, Prohaska, SS, Katzman S, Heffner GC, Stuart JM, Weissman IL. Differential expression of novel potential regulators in hematopoietic stem cells. PloS Genet. 2005; 1:281-294. https://doi.org/10.1371/journal.pgen.0010028.

29. Davies HD, Leusink GL, McConnell A, Deyell M, Cassidy SB, Fick GH, Coppes MJ. Myeloid leukemia in PraderWilli syndrome. J Pediatr. 2003; 142:174-78.

30. Somervaille TC, Cleary ML. Identification and characterization of leukemia stem cells in murine MLL-AF9 acute myeloid leukemia. Cancer Cell. 2006; 10:257-68.

31. Domen J, Cheshier SH, Weissman IL. The role of apoptosis in the regulation of hematopoietic stem cells: overexpression of Bcl-2 increases both their number and repopulation potential. J Exp Med. 2000; 191:253-64.

32. Doan PL, Himburg HA, Helms K, Russell JL, Fixsen E, Quarmyne M, Harris JR, Deoliviera D, Sullivan JM, Chao NJ, Kirsch DG, Chute JP. Epidermal growth factor regulates hematopoietic regeneration after radiation injury. Nat Med. 2013; 19:295-304.
33. Cheshier SH, Morrison SJ, Liao X, Weissman IL. In vivo proliferation and cell cycle kinetics of long-term selfrenewing hematopoietic stem cells. Proc Natl Acad Sci USA. 1999; 96:3120-25.

34. Kiel MJ, He S, Ashkenazi R, Gentry SN, Teta M, Kushner JA, Jackson TL, Morrison SJ. Haematopoietic stem cells do not asymmetrically segregate chromosomes or retain BrdU. Nature. 2007; 449:238-42.

35. Wilson A, Laurenti E, Oser G, van der Wath RC, Blanco-Bose W, Jaworski M, Offner S, Dunant CF, Eshkind L, Bockamp E, Lió P, Macdonald HR, Trumpp A. Hematopoietic stem cells reversibly switch from dormancy to self-renewal during homeostasis and repair. Cell. 2008; 135:1118-29.

36. Yilmaz $\mathrm{OH}$, Valdez R, Theisen BK, Guo W, Ferguson $\mathrm{DO}, \mathrm{Wu} \mathrm{H}$, Morrison SJ. Pten dependence distinguishes haematopoietic stem cells from leukaemia-initiating cells. Nature. 2006; 441:475-82.

37. Zhang J, Grindley JC, Yin T, Jayasinghe S, He XC, Ross JT, Haug JS, Rupp D, Porter-Westpfahl KS, Wiedemann LM, Wu H, Li L. PTEN maintains haematopoietic stem cells and acts in lineage choice and leukaemia prevention. Nature. 2006; 441:518-22.

38. Viatour P, Somervaille TC, Venkatasubrahmanyam S, Kogan S, McLaughlin ME, Weissman IL, Butte AJ, Passegué E, Sage J. Hematopoietic stem cell quiescence is maintained by compound contributions of the retinoblastoma gene family. Cell Stem Cell. 2008; 3:416-28.

39. Ito K, Bernardi R, Morotti A, Matsuoka S, Saglio G, Ikeda Y, Rosenblatt J, Avigan DE, Teruya-Feldstein J, Pandolfi PP. PML targeting eradicates quiescent leukaemia-initiating cells. Nature. 2008; 453:1072-78.

40. Lacorazza HD, Yamada T, Liu Y, Miyata Y, Sivina M, Nunes J, Nimer SD. The transcription factor MEF/ELF4 regulates the quiescence of primitive hematopoietic cells. Cancer Cell. 2006; 9:175-87.

41. Arai F, Hirao A, Ohmura M, Sato H, Matsuoka S, Takubo K, Ito K, Koh GY, Suda T. Tie2/angiopoietin-1 signaling regulates hematopoietic stem cell quiescence in the bone marrow niche. Cell. 2004; 118:149-61.

42. Gérard M, Hernandez L, Wevrick R, Stewart CL. Disruption of the mouse necdin gene results in early post-natal lethality. Nat Genet. 1999; 23:199-202.

43. Chatterjee R, Chattopadhyay S, Law S. Alteration of classical and hematopoiesis specific p53 pathway in the bone marrow hematopoietic stem/progenitor compartment facilitates leukemia progression in experimental mice. Leuk Res. 2016; 47:70-77.

44. Kim I, He S, Yilmaz OH, Kiel MJ, Morrison SJ. Enhanced purification of fetal liver hematopoietic stem cells using SLAM family receptors. Blood. 2006; 108:737-44.

45. Hasegawa K, Yoshikawa K. Necdin regulates p53 acetylation via Sirtuin 1 to modulate DNA damage response in cortical neurons. J Neurosci. 2008; 28:8772-84. 
46. Oravecz-Wilson KI, Philips ST, Yilmaz OH, Ames HM, Li L, Crawford BD, Gauvin AM, Lucas PC, Sitwala K, Downing JR, Morrison SJ, Ross TS. Persistence of leukemia-initiating cells in a conditional knockin model of an imatinib-responsive myeloproliferative disorder. Cancer Cell. 2009; 16:137-48.

47. Mulloy JC, Jankovic V, Wunderlich M, Delwel R, Cammenga J, Krejci O, Zhao H, Valk PJ, Lowenberg B, Nimer SD. AML1-ETO fusion protein up-regulates TRKA mRNA expression in human CD34+ cells, allowing nerve growth factor-induced expansion. Proc Natl Acad Sci USA. 2005; 102:4016-21.

48. Kubota Y, Osawa M, Jakt LM, Yoshikawa K, Nishikawa $\mathrm{S}$. Necdin restricts proliferation of hematopoietic stem cells during hematopoietic regeneration. Blood. 2009; 114:4383-92.

49. Xu H, Valerio DG, Eisold ME, Sinha A, Koche RP, Hu W, Chen CW, Chu SH, Brien GL, Park CY, Hsieh JJ, Ernst P, Armstrong SA. NUP98 Fusion Proteins Interact with the NSL and MLL1 Complexes to Drive Leukemogenesis. Cancer Cell. 2016; 30:863-78.

50. Sumitomo Y, Koya J, Nakazaki K, Kataoka K, TsurutaKishino T, Morita K, Sato T, Kurokawa M. Cytoprotective autophagy maintains leukemia-initiating cells in murine myeloid leukemia. Blood. 2016; 128:1614-24. 